\title{
BMJ Open Nationwide evaluation of the advanced clinical practitioner role in England: a cross-sectional survey
}

\author{
Lauren Jade Fothergill, ${ }^{1}$ Amani Al-Oraibi (D , , Jonathan Houdmont, ${ }^{2}$ \\ Joy Conway (D) , ${ }^{3}$ Catrin Evans (D) , ${ }^{1}$ Stephen Timmons, ${ }^{4}$ Ruth Pearce, ${ }^{5}$ \\ Holly Blake ${ }^{6,7}$
}

\begin{abstract}
To cite: Fothergill LJ, AlOraibi A, Houdmont J, et al. Nationwide evaluation of the advanced clinical practitioner role in England: a crosssectional survey. BMJ Open 2022;12:e055475. doi:10.1136/ bmjopen-2021-055475

- Prepublication history and additional supplemental material for this paper are available online. To view these files, please visit the journal online (http://dx.doi.org/10.1136/ bmjopen-2021-055475)
\end{abstract}

LJF and $A A-0$ are joint first authors.

Received 15 July 2021 Accepted 15 December 2021

Check for updates

(c) Author(s) (or their employer(s)) 2022. Re-use permitted under CC BY-NC. No commercial re-use. See rights and permissions. Published by BMJ.

For numbered affiliations see end of article.

Correspondence to

Professor Holly Blake;

holly.blake@nottingham.ac.uk

\section{ABSTRACT}

Background and study objective In response to growing pressures on healthcare systems, the advanced clinical practice (ACP) role has been implemented widely in the UK and internationally. In England, ACP is a level of practice applicable across various healthcare professions, who exercise a level of autonomy across four domains, referred to as the four pillars of practice (education, leadership, research and clinical practice). A national framework for ACP was established in 2017 to ensure consistency across the ACP role, however current ACP governance, education and support is yet to be evaluated. This study aimed to analyse data from a national survey of the ACP role to inform the development and improvement of policies relating to ACP in the National Health Service (NHS) in England.

Design A cross-sectional survey with free-text comments. Setting The survey was distributed across primary and secondary levels of care to three distinct groups in England, including individual ACPs, NHS provider organisations and Trusts and primary care settings. Participants A total of 4365 surveys were returned, from ACP staff $(n=4013)$, NHS provider organisations and Trusts $(n=166)$ and primary care organisations $(n=186)$.

Results Considerable variation was found in role titles, scope of practice, job descriptions and educational backgrounds of ACPs. Differing approaches to governance were noted, which led to inconsistent ACP frameworks in some organisations. A further challenge highlighted included committing time to work across the four pillars of advanced practice, particularly the research pillar. ACPS called for improvements in supervision and continuing professional development alongside further support in navigating career pathways.

Conclusions A standardised approach may support ACP workforce development in England and enable ACPs to work across the four pillars of practice. Due to the wide uptake of ACP roles internationally, this study has relevance across professions for global healthcare workforce transformation

\section{INTRODUCTION}

Over recent years, health systems such as the United Kingdom's (UK) National Health Service (NHS) have faced considerable pressures associated with workforce shortfalls,
Strengths and limitations of this study

- This is the first large-scale evaluation of the advanced clinical practice (ACP) role across professions, geographical regions and settings.

- Quantitative and free-text qualitative data allow rich exploration of ACP roles and has global implications for workforce transformation.

- The distribution of the online surveys may introduce a gatekeeper bias, although the sample was large and broadly representative.

ageing populations, increasing healthcare costs and more recently, the COVID-19 pandemic. ${ }^{12}$ In response to these challenges, NHS policies such as the NHS Long Term Plan (2019) have focused on transforming the workforce to enhance service provision and optimise standards of care. ${ }^{34}$ To meet growing service demand, NHS policies highlight the increasing need to establish innovative care models and develop advanced roles to contribute to the workforce transformation agenda. ${ }^{4}$ One strategy of importance is the introduction and formalisation of advanced clinical practice (ACP).

ACP is a level of practice that healthcare practitioners can attain. ACP roles span various professions, including nursing, pharmacy, paramedics, occupational therapy and other allied health professions. ${ }^{5}$ ACPs can complement tasks traditionally conducted by doctors, such as primary care duties. ${ }^{6}$ Shortages in healthcare professionals exist in many countries, and increasingly, advanced practice roles have been implemented internationally to maximise workforce capacity and help in workforce retention. ${ }^{7}$ ACP roles have been shown to have positive outcomes on clinical practice, service efficiency and team functioning, with consistently high patient satisfaction. ${ }^{6}$ However, historically, ACP roles have been unregulated and ill-defined, 
leading to a proliferation of positions with different job specifications, educational requirements and scope of practice. ${ }^{8}$ Similar trends have been noted internationally, with levels of advanced practice and education varying considerably across Europe in the absence of educational requirements, limiting opportunities for expanded practice across countries. ${ }^{7}$ The lack of clarity surrounding ACP can result in confusion to the public, employers and commissioners and may impede workforce planning, professional support and development and ultimately patient safety. ${ }^{10}{ }^{11}$ Research in this area is limited but suggests that there may be issues with current ACP governance, including lack of role clarity, inconsistent educational background, scope of practice, as well as training issues including lack of mentorship, support and unclear career pathways. ${ }^{812}$

Health Education England (HEE) is a non-departmental public body, which provides coordination and support for the training and education within England's healthcare workforce. ${ }^{13}$ In 2017, HEE published a 'multiprofessional framework for ACP' to drive national consistency within ACP roles in England, and provide a common understanding across healthcare professions of ACP with agreed education and competency arrangements. ${ }^{14} \mathrm{HEE}$ stipulates that healthcare professionals in ACP roles are educated to Masters level and have developed the skills and knowledge to allow them to take on expanded roles and scope of practice in relation to patient care. While studying for their Masters degree, they are classified as trainee ACPs which incorporates academic learning in a university and workplace-based learning. The university develop the competencies and capabilities to reflect the required knowledge, skills, experiences, behaviours and values in relation to advanced practice and some universities embrace the various Royal College curricula, for example, the Royal College of Emergency Medicine.

While in training, each ACP trainee should have a nominated education supervisor in their workplace. High quality workplace-based supervision is vital in order to achieve the competencies and capabilities required to become a safe and effective ACP. As some ACP roles are new, it is common for workplace-based supervisors to cross traditional professional boundaries. HEE (2020) published a 'Workplace supervision for Advanced Clinical Practice: an integrated multiprofessional approach for practitioner development' which outlines seven fundamental principles to underpin the trainees ACPs workplace-based supervision to enhance patient and professional safety. ${ }^{15}$ These are practice context, competence and capability, multiprofessional registrations, individual learning plan, professional development and transition, integrated approach and finally service development.

While the HEE framework may contribute positively to defining ACP level roles, the impact of this framework on current ACP governance, education and support is yet to be evaluated in practice. Developments in understanding of the ACP role, related workforce strategies, support and training available to ACPs and underpinning governance structures may facilitate improved workforce transformation and planning, which may provide knowledge to international audiences on the impact of implementing an ACP framework.

This paper reports the results of a national survey conducted by Ipsos MORI in 2019, to inform the development and improvement of policies relating to ACP. Ipsos MORI is a social research institute that works closely with national governments, local public services and the not-for-profit sector to ensure that research makes a difference for decision makers and communities. This work was commissioned by HEE to survey the advancing practice workforce and key stakeholders. The aim of the survey was to provide information on the role of the advanced practitioner and to inform future work developing and improving advancing practice within the NHS in England. This survey will also provide a baseline to evaluate these future developments of the role of advanced practitioners. Specific objectives were as follows:

- To better understand the patterns of governance, education, clinical practice, accreditation and workbased learning in ACP roles.

- To explore the challenges affecting advanced-level practice implementation by sector, specialty and profession in England.

- To assess the outcomes and impacts of advanced-level practice roles by sector, specialty and profession in England.

- To identify the key gaps in governance, education, clinical practice, accreditation and work-based learning.

- To identify the most urgent areas for future investigation or provision.

\section{METHODS}

\section{Study design}

A mixed-method online survey was distributed via HEE to trainee and current ACPs in England. ${ }^{16}$ The survey utilised both quantitative and qualitative items in recognition of the multifaceted nature of the aim and objectives of the study. ${ }^{17}$

\section{Materials and procedure}

To evaluate current governance, education and support within advanced-level practice, HEE distributed three distinct questionnaire surveys to ACPs (online supplemental file 1), NHS provider organisations and Trusts (online supplemental file 2) and primary care organisations (online supplemental file 3). The questionnaire surveys were developed by the HEE AHP Lead and HEE ACP Steering Group member, HEE project manager, HEE Regional Chief Nurse, Deputy Chief Nurse, HEE Head of Clinical Education Transformation, HEE Advancing Practice Faculty Lead and members from the Ipsos MORI team. They were trialled with AAPE-UK members and refined by the HEE AHP Lead and HEE Steering group member, HEE Head of Clinical Education Transformation and Ipsos MORI. This trial helped in the decision to 
distribute distinct questionnaires for participants' recruitment to allow for the exploration of ACP practice across different organisations, professions and settings. Data collection took place between 21 August and 1 November 2019.

The surveys were disseminated by a nominated survey lead within each region to the organisations and contacts identified by HEE. This lead was responsible for communication and engagement with the target groups in order to identify the relevant participants and to encourage a good response to the surveys. The subsequent method of dissemination beyond this across the HEE local offices, NHS organisation, ACP level staff and primary care organisations is outlined. For the ACP survey, organisational leads were responsible for dissemination, sending the survey to managers or professional leads to forward onto staff who considered themselves to be working at the level of an ACP, or ACP trainee, regardless of their job titles. For the NHS provider organisations and Trusts' survey, there was a named organisational lead (identified by HEE) responsible for responding to the survey. This person was typically responsible for workforce development within their Trust and worked with relevant colleagues and departments to collect the information required. For the primary care organisations, a named Clinical Commissioning Group lead was responsible for sending the survey out to relevant GP practices within their area. Practice Managers or GPs were then asked to complete the survey on behalf of their practice. Early exploration with HEE showed that it would not be possible to define the target population for the study at the outset, as the contact details required for distribution of each survey were held by a range of disparate and diverse organisations who took responsibility for onwards distribution, making it difficult to accurately collate information. Therefore, a programme of engagement and collaborative working was undertaken by HEE to engage local offices, NHS organisations, ACP level staff and primary care organisations in awareness-raising about the study and in onwards distribution of the survey. This was achieved through workshops, posters, information leaflets and an online webinar video.

\section{Data analysis}

Data from the quantitative and qualitative elements of the survey were analysed separately, and then triangulated and interpreted. ${ }^{16}$ Quantitative data were analysed using descriptive statistics (mean, $\mathrm{SD}$ and frequencies) in IBM SPSS Statistics for Windows, version 26 (IBM Corp., Armonk, N.Y., USA). Descriptive statistical operations were performed separately on data from each of the three surveys, to identify differences in roles and scope across various settings.

Free-text responses were analysed using a semantic level inductive thematic analysis in NVivo V.12. ${ }^{18}$ Two researchers (AA-O and LJF) familiarised themselves with the data, then coded the data using two existing conceptual frameworks to align the data analysis approach to the research questions. These frameworks included the four pillars of advanced practice set out in the HEE multiprofessional framework for ACP and Bonsall multiprofessional framework for ACP and Bonsall and Cheater's (2008) framework which considers the development, barriers and facilitators of the ACP role. ${ }^{6}$ These two frameworks were utilised as they presented simple concepts to evaluate the ACP roles with, which were thought to facilitate a descriptive analysis of the free-text responses, rather than an in-depth analysis. The two frameworks facilitated code creation, with the themes presented in relation to the research questions of the study. Quantitative and qualitative data were merged by highlighting similarities in the data, to enrich findings and synthesise complementary results. ${ }^{16}$

\section{RESULTS}

A total of 4365 surveys were returned, of which 4013 surveys were from ACP staff ( $76.6 \%$ female, $n=3073$ ), 186 surveys were from primary care organisations and 166 surveys were returned from various NHS provider organisations and Trusts.

\section{Governance and regulations \\ Variability of the ACP role}

ACP job titles were varied and inconsistent (table 1). While nine out of 10 respondents of the ACP survey had a job description for their ACP post, many respondents stated that the job description was unclear and did not reflect their current roles. This inconsistency in ACP titles and job roles was suggested to contribute to discrepancies over banding between Trusts, and a lack of recognition of the ACP role within the wider team.

There is no job description and I feel very frustrated and the 'just get on with it' approach that seems to exist here and the lack of a defined role for me to go into once finished training. (RID:1875, Adult Nurse)

\section{Governance structures}

Participants in the ACP survey highlighted the importance of appropriate governance but suggested that there was a lack of a defined formal structure and provision for ACPs, leading to an inconsistent framework and dissatisfaction among ACPs.

There is no clear governance structure in place at present and no clear Advanced Practice lead. (RID:10258, Adult Nurse)

ACP's knowledge about the existence of governance was low (table 2), with fewer than one-third of respondents having access to meetings or a forum to discuss advanced practice $(31.6 \%, \mathrm{n}=1997)$, and only a small proportion were able to identify a lead for ACP $(29.9 \%, n=1886)$ or an organisational policy on advanced practice $(n=1155$, $18.2 \%)$. Sixty-one per cent of respondents to the primary care survey reported that the practice had a process or 
Table 1 Job titles $(n=4178)$

N N

\begin{tabular}{lrll}
\hline $\begin{array}{l}\text { Acute care } \\
\text { practitioner }\end{array}$ & 13 & District nurse lead & 6 \\
$\begin{array}{l}\text { Acute nurse } \\
\text { practitioner }\end{array}$ & 14 & Education lead/consultant & 23 \\
$\begin{array}{l}\text { Acute oncology } \\
\text { practitioner }\end{array}$ & 8 & Emergency care practitioner & 44 \\
$\begin{array}{l}\text { Adult nurse } \\
\text { practitioner }\end{array}$ & 14 & Emergency nurse practitioner & 38 \\
$\begin{array}{l}\text { Advanced clinical } \\
\text { practice }\end{array}$ & 390 & $\begin{array}{l}\text { Extended scope } \\
\text { physiotherapist }\end{array}$ & 18 \\
\hline $\begin{array}{l}\text { Advanced } \\
\text { community } \\
\text { practitioner }\end{array}$ & 12 & Extended scope practitioner & 15 \\
\hline $\begin{array}{l}\text { Advand } \\
\text { nation }\end{array}$ & & & \\
\hline
\end{tabular}

practitioner

\begin{tabular}{|c|c|c|c|}
\hline $\begin{array}{l}\text { Advanced critical } \\
\text { care practitioner }\end{array}$ & 43 & First contact practitioner & 18 \\
\hline $\begin{array}{l}\text { Advanced } \\
\text { musculoskeletal }\end{array}$ & 17 & $\begin{array}{l}\text { Gastroenterology nurse } \\
\text { specialist }\end{array}$ & 6 \\
\hline \multicolumn{4}{|l|}{ Practitioner } \\
\hline $\begin{array}{l}\text { Advanced nurse } \\
\text { practitioner }\end{array}$ & 645 & Head of community services & 3 \\
\hline $\begin{array}{l}\text { Advanced } \\
\text { occupational } \\
\text { therapist }\end{array}$ & 20 & $\begin{array}{l}\text { Highly specialist clinical/ } \\
\text { principal psychologist }\end{array}$ & 5 \\
\hline \multirow[t]{2}{*}{$\begin{array}{l}\text { Advanced } \\
\text { orthopaedic } \\
\text { practitioner }\end{array}$} & 10 & $\begin{array}{l}\text { Inflammatory bowel disease } \\
\text { clinical }\end{array}$ & 7 \\
\hline & & Specialist & \\
\hline $\begin{array}{l}\text { Advanced } \\
\text { paramedic } \\
\text { practitioner }\end{array}$ & 26 & $\begin{array}{l}\text { Lead advanced clinical } \\
\text { practitioner }\end{array}$ & 10 \\
\hline $\begin{array}{l}\text { Advanced pharmacy } \\
\text { practitioner }\end{array}$ & 26 & Lead chaplain & 3 \\
\hline $\begin{array}{l}\text { Advanced } \\
\text { physiotherapy }\end{array}$ & 111 & Lead practitioner & 4 \\
\hline \multicolumn{4}{|l|}{ Practitioner } \\
\hline Advanced podiatrist & 5 & Manager/clinical manager & 71 \\
\hline $\begin{array}{l}\text { Advanced } \\
\text { radiographer }\end{array}$ & 58 & Matron/community matron & 59 \\
\hline
\end{tabular}

\section{Practitioner}

\begin{tabular}{|c|c|c|c|}
\hline $\begin{array}{l}\text { Advanced } \\
\text { sonographer } \\
\text { practitioner }\end{array}$ & 16 & $\begin{array}{l}\text { Musculoskeletal practitioner } \\
\text { specialist }\end{array}$ & 4 \\
\hline $\begin{array}{l}\text { Advanced specialist } \\
\text { speech and } \\
\text { language }\end{array}$ & 15 & Nurse lead/consultant & 167 \\
\hline $\begin{array}{l}\text { Advanced } \\
\text { ultrasound } \\
\text { practitioner }\end{array}$ & 4 & Nurse manager & 20 \\
\hline Associate director & 5 & Nurse practitioner & 147 \\
\hline \multirow[t]{2}{*}{$\begin{array}{l}\text { Associate director of } \\
\text { nursing }\end{array}$} & 3 & $\begin{array}{l}\text { Older persons assessment } \\
\text { and }\end{array}$ & 3 \\
\hline & & liaison practitioner & \\
\hline Cancer nurse & 31 & $\begin{array}{l}\text { Older persons nurse } \\
\text { practitioner }\end{array}$ & 15 \\
\hline $\begin{array}{l}\text { Specialist/ } \\
\text { practitioner }\end{array}$ & & & \\
\hline
\end{tabular}

Continued
Table 1 Continued

\begin{tabular}{|c|c|c|c|}
\hline & $\mathbf{N}$ & & $\mathbf{N}$ \\
\hline Cardiac specialist & 32 & $\begin{array}{l}\text { Paediatric advanced clinical } \\
\text { practitioner }\end{array}$ & 4 \\
\hline $\begin{array}{l}\text { Cognitive } \\
\text { Behavioural } \\
\text { Therapist }\end{array}$ & 7 & Paediatric nurse & 15 \\
\hline $\begin{array}{l}\text { Children's specialist } \\
\text { nurse }\end{array}$ & 11 & Paramedic practitioner & 48 \\
\hline Clinical endoscopist & 4 & Pharmacist clinical lead & 22 \\
\hline $\begin{array}{l}\text { Clinical lead } \\
\text { dietician }\end{array}$ & 22 & Physiotherapist practitioner & 15 \\
\hline $\begin{array}{l}\text { Clinical lead for } \\
\text { minor }\end{array}$ & 11 & Practice educator & 3 \\
\hline
\end{tabular}

\section{Injuries/illness}

$\begin{array}{lclr}\text { Clinical lead medical } & 20 & \text { Practice nurse lead } & 19 \\ \begin{array}{l}\text { Clinical lead non- } \\ \text { medical }\end{array} & 11 & \text { Principal pharmacist } & 5 \\ \begin{array}{l}\text { Clinical lead } \\ \text { occupational }\end{array} & 6 & \text { Principal radiographer } & 4\end{array}$

$\begin{array}{llll}\text { Therapist } & & & \\ \text { Clinical lead } & 36 & \text { Radiographer lead } & 17\end{array}$

physiotherapist

\begin{tabular}{lclc}
$\begin{array}{l}\text { Clinical lead } \\
\text { psychologist }\end{array}$ & 5 & Reporting radiographer & 33 \\
$\begin{array}{l}\text { Clinical lead } \\
\text { specialist }\end{array}$ & 88 & $\begin{array}{l}\text { Respiratory nurse specialist/ } \\
\text { lead }\end{array}$ & 24 \\
\hline
\end{tabular}

\begin{tabular}{|c|c|c|c|}
\hline Physiotherapist & & Specialist & \\
\hline $\begin{array}{l}\text { Clinical nurse } \\
\text { endoscopist }\end{array}$ & 40 & $\begin{array}{l}\text { Respiratory physiotherapist } \\
\text { specialist }\end{array}$ & 12 \\
\hline $\begin{array}{l}\text { Clinical nurse } \\
\text { specialist }\end{array}$ & 289 & $\begin{array}{l}\text { Senior/team leader } \\
\text { physiotherapist }\end{array}$ & 15 \\
\hline $\begin{array}{l}\text { Clinical podiatrist } \\
\text { lead }\end{array}$ & 9 & Senior advanced practitioner & 26 \\
\hline Clinical podiatrist & 22 & $\begin{array}{l}\text { Senior clinical/biomedical } \\
\text { scientist }\end{array}$ & 5 \\
\hline
\end{tabular}

\section{Specialist/surgeon}

Clinical practitioner $24 \quad$ Senior clinical pharmacist 13

$\begin{array}{llll}\text { Clinical scientist } & 8 & \text { Senior nurse practitioner } & 38\end{array}$

Clinical specialist 4 Senior nurse specialist 5

extended scope

Practitioner

\begin{tabular}{lclc}
$\begin{array}{l}\text { Clinical specialist } \\
\text { occupational }\end{array}$ & 23 & Senior occupational therapist & 5 \\
$\begin{array}{l}\text { Therapist } \\
\begin{array}{l}\text { Clinical specialist } \\
\text { sonographer }\end{array}\end{array}$ & 3 & Senior radiographer & 13 \\
$\begin{array}{l}\text { Community clinical } \\
\text { practitioner }\end{array}$ & 4 & Site nurse practitioner & 12 \\
$\begin{array}{l}\text { Community nurse } \\
\text { specialist }\end{array}$ & 20 & Sonographer lead & 27 \\
$\begin{array}{l}\text { Community } \\
\text { specialist } \\
\text { practitioner }\end{array}$ & 4 & Specialist midwife & 3 \\
$\begin{array}{l}\text { Consultant/team } \\
\text { lead dietician }\end{array}$ & 5 & Specialist paramedic & 17 \\
\hline
\end{tabular}

Continued 


\begin{tabular}{|c|c|c|c|}
\hline & $\mathbf{N}$ & & $\mathbf{N}$ \\
\hline $\begin{array}{l}\text { Consultant clinical } \\
\text { scientist }\end{array}$ & 16 & Specialist pharmacist & 13 \\
\hline Consultant midwife & 11 & Specialist practitioner & 5 \\
\hline $\begin{array}{l}\text { Consultant } \\
\text { musculoskeletal } \\
\text { practitioner }\end{array}$ & 2 & $\begin{array}{l}\text { Specialist practitioner critical/ } \\
\text { urgent care }\end{array}$ & 4 \\
\hline $\begin{array}{l}\text { Consultant } \\
\text { paramedic }\end{array}$ & 3 & Specialist radiographer & 12 \\
\hline \multirow[t]{2}{*}{$\begin{array}{l}\text { Consultant } \\
\text { pharmacist }\end{array}$} & 17 & $\begin{array}{l}\text { Speech and therapy } \\
\text { language }\end{array}$ & 33 \\
\hline & & Specialist & \\
\hline $\begin{array}{l}\text { Consultant } \\
\text { physiotherapist }\end{array}$ & 17 & Surgical care practitioner & 30 \\
\hline Consultant podiatrist & 7 & $\begin{array}{l}\text { Trainee Advanced Clinical } \\
\text { Practitioner }\end{array}$ & 7 \\
\hline $\begin{array}{l}\text { Consultant } \\
\text { practitioner trainee }\end{array}$ & 2 & Team lead practitioner & 9 \\
\hline $\begin{array}{l}\text { Consultant } \\
\text { practitioner }\end{array}$ & 5 & Trainee ACP & 396 \\
\hline $\begin{array}{l}\text { Consultant } \\
\text { psychologist }\end{array}$ & 11 & Trainee specialist practitioner & 13 \\
\hline $\begin{array}{l}\text { Consultant } \\
\text { radiographer }\end{array}$ & 36 & $\begin{array}{l}\text { Trainee surgical care } \\
\text { practitioner }\end{array}$ & 7 \\
\hline $\begin{array}{l}\text { Consultant therapist/ } \\
\text { CT lead }\end{array}$ & 3 & $\begin{array}{l}\text { Urology nurse lead/ } \\
\text { consultant }\end{array}$ & 14 \\
\hline $\begin{array}{l}\text { Critical care } \\
\text { outreach nurse }\end{array}$ & 21 & Ward sister & 11 \\
\hline $\begin{array}{l}\text { Critical care } \\
\text { outreach specialist }\end{array}$ & 9 & No answer & 9 \\
\hline $\begin{array}{l}\text { Deputy director/lead } \\
\text { pharmacist }\end{array}$ & 2 & Other & 152 \\
\hline $\begin{array}{l}\text { Diabetes specialist } \\
\text { nurse }\end{array}$ & 26 & & \\
\hline
\end{tabular}

ACP, advanced clinical practice.

governance structure in place to support and monitor the impact of ACP roles.

\section{Education}

The majority of ACPs were trained to at least degree level $(82.7 \%, \mathrm{n}=2886)$ and more than half to master's level $(56.9 \%, \mathrm{n}=1985)$, however the subjects studied varied considerably.

ACP respondents $(12 \%, n=482)$ shared positive experiences of the educational support and training they had received and the improvements in educational opportunities over the last few years.

I have been on a training role for 18 months which has involved watching assessments, teaching and feedback. This has been very helpful in order to allow me to start a job in advanced practice. (RID:8462, Physiotherapist)

Almost 37\% ( $\mathrm{n}=1602)$ of the ACP survey respondents were currently undertaking masters level training. There
Table 2 ACP reports relating to forms of governance

\begin{tabular}{ll}
$\begin{array}{l}\text { Does your organisation have any of the } \\
\text { following? }\end{array}$ & $\mathbf{N}(\%)$ \\
\hline $\begin{array}{l}\text { Lead for advanced practice } \\
\text { Forum or meetings where professionals for } \\
\text { different groups can discuss advanced practice }\end{array}$ & $1987(29.9)$ \\
\hline $\begin{array}{l}\text { Organisational policy on advanced practice } \\
\text { None of these }\end{array}$ & $1155(18.2)$ \\
\hline Do not know & $511(8.1)$ \\
\hline
\end{tabular}

ACP, advanced clinical practice.

were frequent reports of ACPs feeling overwhelmed by the volume of academic work alongside their clinical workloads. ACPs often highlighted the lack of protected study time offered by their organisation outside of study days to attend taught sessions. ACPs felt that this was the primary reasons for high stress and the 'immense struggle' experienced by ACPs, hindering their ability to fulfil their competencies. The impact of using personal time to complete studies had a negative impact on ACP well-being:

In the first year I had to work $70 \%$ of my time as a band 5 nurse with only $30 \%$ of my time being released to attend university (weekly) and gain the clinical exposure necessary to complete an extensive clinical portfolio of assessments and achievements across the 4 pillars (16 hours a month). This was extremely stressful, caused me significant anxiety and allowed me very little rest time. I nearly burnt out. (RID:4802, Paediatric Nurse)

Respondents challenged the concept of 'advanced' being based on educational qualifications and advocated that clinical experience should be considered in ACP accreditation.

I also don't think having an MSc in advanced practice makes you advanced. We need time under your belt. You can get a MSc but unless you have seen the 1000 chest pains or 1000 abdominal pains or seen things that others will not have seen due to experience, then you are not advanced. (RID:4393, Adult Nurse)

\section{Supervision and support}

Although ACPs reported that the role had evolved over the years in terms of support, there was significant inconsistency across organisations, and a mismatch between the views of organisational representatives and ACPs regarding the amount of supervision offered, and the processes for how it was provided.

In the NHS organisations and Trust survey, 42.8\% $(n=71)$ respondents reported that their organisation had a policy relating to supervision (regarding time allocated, when and where supervision should take place) and $65.1 \%(\mathrm{n}=108)$ reported that their ACP workforce was required to have capability frameworks aligned to their 
areas of clinical practice. However, ACP respondents indicated that only $32 \%$ of ACPs $(n=1241)$ had a formal structure for their supervision; in the primary care survey, one in five $(\mathrm{n}=38,20 \%)$ indicated there was no policy for ACP supervision in place. Supervision frequency was varied and there was no consistency in the guidance structure for supervision, with ACPs reporting that supervision was provided by numerous stakeholders including higher education institution $(8.2 \%, \mathrm{n}=98)$, organisation/Trust $(53.7 \%, \mathrm{n}=638)$, service $(13.1 \%, \mathrm{n}=156)$, professional group $(13.3 \%, \mathrm{n}=158)$, other $(7.1 \%, \mathrm{n}=85)$ and 'do not know' $(4.5 \%, \mathrm{n}=54)$.

Despite considerable variability in provision, those who had received mentoring support unanimously viewed this as a positive experience:

I feel very supported within my Trust for my training. We have regular supervision meetings monthly and have ARCP (Annual Review of Competency Progression) 6 monthly. Our ACP supervisor is always willing to meet up to discuss or review portfolio or anything else. (RID:10706, Mental health nurse)

However, many ACPs experienced difficulty in accessing practical support in terms of resources and funding, and this was clearly inequitable across organisations. One in four ACP staff (26.3\%, n=138) had made a personal financial contribution to their studies. The lack of funding, combined with limited support was perceived by ACPs to restrict their performance in the ACP role and protected time for studies was flagged by NHS Trusts as an area for improvement.

It is extremely frustrating that staff such as myself are having to fully self-fund training to work at this advanced level. (RID:1462, Podiatrist)

Support to undertake master level study-time \& finance-difficult to achieve at organisation level against competing demands. Needs Universities to open up the apprenticeship route as availability is limited this academic year. Also disadvantages those that have undertaken some master level study but need to complete their MSc. (RID: 1160)
ACPs described how their development pathway had been driven by personal needs rather than a consistent and standardised national policy. The lack of a defined structure was viewed as problematic, and the language used by ACPs alluded to worry and concern about their individual competencies and career progression, associated with the level of guidance, supervision and support provided. This led to a perceived lack of direction and concern about the future sustainability of the ACP role.

There is no standard competencies or practice for these roles. Also, where is the future of these roles? (RID:3998, Adult Nurse)

\section{Working in accordance with the HEE framework Knowledge of the HEE framework}

Respondents' current level of knowledge of HEE's 2017 multiprofessional framework for ACP was indicated on a scale ranging from 'a great deal' to 'never heard of' (figure 1). NHS organisations had greater knowledge of the HEE framework, compared with individual ACPs. Knowledge of the HEE framework in primary care settings was particularly poor, as $36 \%(n=67)$ of respondents stated that they had never heard of the framework or had heard of it but knew nothing about it, while $40.4 \%$ $(n=85)$ reported that none or hardly any staff working at the ACP level had been mapped against the HEE framework. In primary care settings, clinical practice was the area most likely to be prioritised for mapping against the HEE Framework (27.4\%, n=51), although 46.2\% ( $\mathrm{n}=86)$ of respondents did not complete the item of framework and organisational mapping priorities may be low.

\section{The four pillars of advanced practice}

There was a widely held belief across the three surveys that the four pillars of advanced practice were integral to ACP roles. Yet mapping of ACP roles to the framework was not common, and the clinical pillar of practice appeared to be consistently prioritised over the remaining three pillars. This was attributed to the demanding nature of the role, making it challenging to allocate time to the other three pillars.

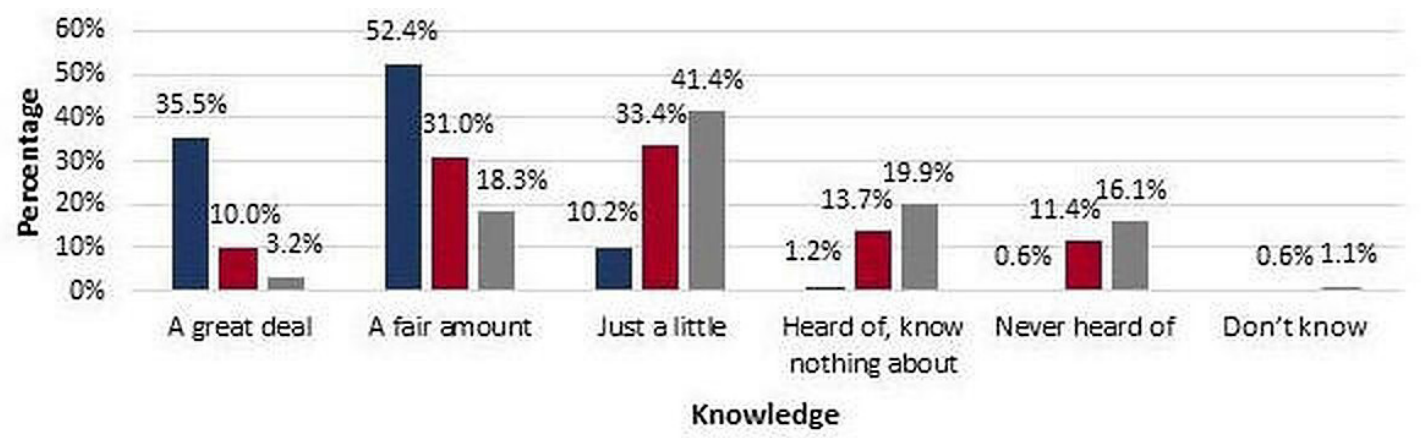

@NHS organisations survey $\because$ ACP staff survey $\quad$ Primary care survey

Figure 1 Knowledge of multiprofessional framework for advanced clinical practice. ACP, advanced clinical practice; NHS, National Health Service. 
Table 3 Framework priorities from the primary care survey $(n=186)$

\begin{tabular}{lc}
\hline & N (\%) \\
\hline Clinical practice & $51(27.4)$ \\
Leadership and management & $14(7.5)$ \\
Education & $8(4.3)$ \\
Research & $1(0.5)$ \\
We do not have a priority & $26(14.0)$ \\
No response & $86(46.2)$ \\
\hline
\end{tabular}

There is no recognition that advanced practitioners should be working within the 4 pillars-the emphasis is on clinical work and no options for research, education or management. (RID:11429, Podiatrist)

The research pillar was a neglected area of focus, with only $0.5 \%$ of primary care trusts stating it was a framework priority (table 3 ). Only $11 \%$ of the ACP survey respondents $(n=979)$ reported that they were involved in research (table 4). Research findings were most often disseminated within the Trusts and organisations, with $70.9 \% \quad(n=2844)$ of ACPs reporting having presented their research in this way, and locally (36.7, n=1471). A minority of ACPs had disseminated research nationally $(24.7 \%, \mathrm{n}=992)$ or internationally $(9.6 \%, \mathrm{n}=386)$.

\section{DISCUSSION}

\section{Main findings of this study}

This is the largest national workforce survey of the ACP workforce in England, with global significance for healthcare workforce transformations, given the overlap of issues highlighted in England to an international context. A high level of variation in roles and specialities across ACPs was revealed, which subsequently led to confusion around the scope and expectations of the role and contributed to the lack of recognition of ACPs within teams. Significant variation in established governance approaches and defined ACP competencies across

\begin{tabular}{lc}
\hline $\begin{array}{l}\text { Table } 4 \text { ACP survey reports of involvement in research } \\
(\mathrm{n}=4013)\end{array}$ \\
\hline $\begin{array}{l}\text { In which, if any, of the following areas of } \\
\text { research are you involved? }\end{array}$ & $\mathbf{N}(\%)$ \\
\hline Quality improvement & $2187(24.4)$ \\
\hline Service evaluation & $2137(23.8)$ \\
\hline Economic evaluation of practice & $290(3.2)$ \\
\hline Research & $979(10.9)$ \\
\hline Audit & $2696(30.0)$ \\
\hline Other & $119(1.3)$ \\
\hline None of these & $543(6.0)$ \\
\hline Do not know & $30(0.3)$ \\
\hline
\end{tabular}

ACP, advanced clinical practice. employers was found. These inconsistent frameworks for ACPs contributed to frustration and demotivation among ACP staff. Significant variation in educational backgrounds of those in ACP roles was highlighted. Although participants acknowledged that supervision and support levels were evolving, considerable variation in the amount and quality of training and support was found across different professions and settings. Participants called for a defined career pathway for ACPs, to influence ongoing development, motivation and retention. ACP knowledge of the HEE framework was significantly lower than that of employing organisations. Few ACP roles were mapped onto the framework, and there was a clear focus on the clinical pillar, compared with the leadership, education and research pillars. Reasons for the neglect of other pillars included high workloads and competing time pressures in a clinical environment.

\section{Lack of standardised governance structures and role regulation}

Governance structures were viewed as important by ACPs and NHS provider organisations to support and develop ACP employees and ensure effective incorporation of the role into the organisational structure. However, in the absence of national guidance, the responsibility of forming governance structures for advanced practice was determined by each NHS Trust or organisation, leading to significant variation in established governance approaches and definitions of ACP competencies across employers. Although the HEE framework provides a definition of the ACP role and scope, there is little guidance for employers regarding suitable and supportive governance structures. ${ }^{519}$ Although the lack of national guidance on ACP governance has been discussed in literature, ${ }^{819}$ there are no prior studies specifically exploring ACP governance within healthcare settings in the UK. This study highlighted challenges faced by NHS Trusts, organisations and primary care settings to establish governance structures. Organisations spoke of specific barriers to establishing governance structures, including time commitments, lack of knowledge surrounding ACP competencies and subsequent reduced confidence in establishing ACP frameworks and governance structures. NHS provider organisations and Trusts suggested the creation of a national agenda for ACP roles, to provide advice on formally organising ACPs, alongside a standardised competency framework across all specialities. International studies have shown that governance is crucial in implementing ACP roles effectively into the workforce, however regulatory approaches require country-specific evaluations. ${ }^{20}$ Further research to investigate appropriate regulatory approaches for ACPs in England may facilitate a standardised governance structure for advanced roles.

In line with recent reviews, this study identified a high level of variation in role and specialities across ACPs. ${ }^{12}$ NHS provider organisations, Trusts and ACP staff reported great inconsistencies in ACP job titles and roles, which has been demonstrated in other studies 
investigating variability in nursing titles in the UK. ${ }^{11}$ The historic absence of regulation in ACP role definition has resulted in the proliferation of professional titles and roles, causing confusion among ACPs regarding the functions, scope and expectations of their role. ${ }^{6}{ }^{12}$ Although most ACPs reported having a job description, it was commonly stated that job descriptions were unclear, and in some cases did not reflect their current roles. The inconsistency in ACP roles was suggested to contribute to a lack of recognition of the ACP role within the team. ${ }^{6}$ ACP respondents suggested that ACP job titles should be harmonised in healthcare. This may serve to enhance professional identity, potentially curb the proliferation of titles, enable clarity in job scope, improve cohesion of ACPs within the wider medical team and potentially enhance quality of care. ${ }^{11} 12$ It can be argued that the lack of clarity in ACP roles and scope of practice may contribute to difficulties in establishing governance structures, therefore exacerbating other challenges within the ACP workforce.

\section{Diversity in education, supervision, and support}

In line with previous research, this study showed great variability in the education and training undertaken by ACPs. ${ }^{12}$ Although over half of ACPs held a Masters degree, the subjects studied varied considerably. Differing educational and training routes have led to advanced practitioners working with quite different skill sets, competencies, knowledge and experience, which may cause confusion among other healthcare professionals regarding the competencies of ACP roles. ${ }^{62}$ Although ACP was defined officially in 2017 by HEE, this study suggests that significant variation in the educational backgrounds of ACPs still exists, likely originating from the historic development of the ACP role, forming organically and asynchronously. Similar variations in educational backgrounds in advanced practice roles have been noted in international studies, suggesting a need to further standardise educational requirements. ${ }^{722}$ This study suggests stating an education requirement for ACP entry is not sufficient at standardising educational backgrounds. Further efforts are required to reduce the variability in qualifications undertaken by ACPs. ${ }^{21}$ This may enhance clarity regarding the ACP roles among healthcare professionals (including ACPs themselves), and other stakeholders, to enable the development of consistent clinical governance processes.

There was consensus from respondents that the ACP role had evolved over the years in terms of progression, supervision and support. ${ }^{12}$ However, ACP respondents reported ongoing concerns regarding the variability and quality of training across different professions and settings. Supervision was highlighted as an area of concern, with respondents stating that supervision came from a variety of sources and at differing frequencies, particularly in primary care settings. ACPs reported vast differences in the numbers of study days, financial and professional support provided to them to complete their training with many ACPs having to financially support their own development, which is likely to generate inequality of opportunity. ACPs also acknowledged the need for a defined career pathway, which can influence ongoing development, motivation and retention. ${ }^{12}$ International studies have highlighted similar issues, with supervisors lacking understanding of the advanced practice role, leading to underutilisation and lack of career development. ${ }^{23}$ Continuing professional development is important to career satisfaction and supervision can ensure competency and quality of practice. ${ }^{10}$ Further support is required to support high-quality supervision, support and training for ACPs nationally, to enhance ACP professional development and career progression.

\section{Working in accordance with the HEE framework}

Within the 2017 HEE framework, the four pillars of advanced practice represent the pinnacle focus point of ACP's 'core capabilities', which transferred to respondents, who held the belief that the four pillars of advanced practice were integral to the ACP roles. However, we identified a mismatch between organisations' and individual ACPs' knowledge of the ACP framework, since Trusts had a high level of knowledge of the HEE framework compared with ACP. There was also variability in knowledge between settings since knowledge was lower in primary care organisations. Knowledge and awareness did not necessarily translate into action since alignment of ACP roles to the HEE multiprofessional framework was not common. Prioritisation for mapping roles to the framework was particularly low in primary care settings.

Our study has established a need to increase understanding of the HEE multiprofessional framework among ACPs and their employing organisations, particularly in primary care settings, and organisations needs further support to enable them to map ACP roles into HEE's multiprofessional framework.

In this study, although several ACP job descriptions spanned the four pillars, respondents spoke of the clear focus on the clinical pillar of practice. Compliance with the four pillars was not necessarily acknowledged within NHS provider organisations, Trusts and primary care settings and respondents reported significant challenges and barriers to engaging with the educational, leadership and research pillars. The main barriers to engagement were high workloads, limited time or resources and competing pressures in a clinical environment. There was particular inactivity with relation to engagement in research and ACPs require time, resources and support for research activity and dissemination. This would contribute to personal development and facilitate sharing of good practice nationally and internationally. Although it may not be feasible or necessary to allocate equal time to each pillar, it is important to understand and acknowledge each of the four pillars within the ACP job roles, where a different attention can be paid to each one, but all are incorporated to ensure the core capabilities of ACPs reupheld. 
The importance and added value of clinical, leadership, education and research aspects on practice are widely reported. ${ }^{24} 25$ Developing research and leadership skills for advanced practitioners have shown to contribute to building capacity in multidisciplinary teams, developing new initiatives for healthcare delivery and implementing evidence-based clinical practice. ${ }^{24}$ Clarity around the importance and priority of the four pillars of advanced practice is needed, to ensure employers allocate adequate resources and support ACPs to work across all four pillars. $^{25}$

\section{Strengths and weaknesses of the study}

This is the first large-scale national evaluation of the ACP role in England since the 2017 HEE framework was established and it has global relevance for healthcare workforce transformation. The use of a cross-sectional survey with qualitative free-text responses allowed for the exploration of both the distribution and variety of roles, education and support across ACP roles and gain further understanding into the impact of these variations. ${ }^{26}$ It was not possible to determine an accurate response rate since stakeholders at the organisations were asked to distribute the online survey. However, the survey was widely distributed across regions, ACP roles and settings and therefore provides a comprehensive insight into the ACP role across different professions and organisations, and the data presented highlight the similarities and differences across settings. Although the survey was sent to self-identified ACPs rather than strictly limited to those who held the title of ACP, in practice, there is little consistency in who regards themselves as an ACP and limiting the survey distribution to those holding the title of ACP would have limited the representation of ACPs experiences. Therefore, surveys were sent widely to capture a range of views from participants who regarded themselves to be working at an advanced level, regardless of their job title. Further standardisation of ACP definitions, roles and titles in practice will facilitate the identification of ACPs for future evaluative studies.

\section{RECOMMENDATIONS}

\section{Governance and regulations}

- There is a need to standardise job titles and descriptions for ACPs to ensure role recognition and support.

- There is a need for a structured governance framework for ACP roles within organisations across sectors, with guidelines on operational support and a visible lead for ACP. Guidelines providing information on operational support for ACPs may enable Trusts and organisations to improve the quality and credentials of the employees in ACP roles. An evaluation of current ACP governance may inform appropriate strategies in England.

- There should be a standard competency framework for ACPs that is applicable across specialities.
- Clear career pathways for ACPs should be established, to maximise retention and job satisfaction.

\section{Education and support}

- There is a need to further standardise required education and training for ACP roles across all specialities.

- There should be systems in place within organisations, and particularly primary care settings, to ensure ACPs have access to clinical supervision, continuing professional development and structured mentorship. Guidelines on providing adequate supervision for ACPs may be considered.

\section{Working in accordance with the HEE framework}

- There is a need to increase the level of knowledge of HEE's multiprofessional framework for ACP, particularly in primary care settings.

- Further support should be given to employing organisations, to enable them to map ACP roles onto HEE's multiprofessional framework.

- There is a need to highlight the value and importance of each of the four pillars of practice to employers, to encourage the allocation of adequate resources and support for ACPs to work across all four pillars.

- Increased efforts are needed to support ACPs with national and international research engagement to support professional development and share best practice.

\section{CONCLUSION}

As the first large-scale evaluation of the ACP role, this study highlights the need to establish structure surrounding the ACP role, relating to standardisation of job titles and descriptions, improved governance of advanced practice professions, standardised supervision approaches, improved knowledge and compliance with the HEE framework and further development of professional support for ACPs. This study has national and international implications for ACP workforce development.

\section{Author affiliations}

${ }^{1}$ School of Health Sciences, University of Nottingham, Nottingham, UK

${ }^{2}$ School of Medicine, University of Nottingham, Nottingham, UK

${ }^{3}$ Centre for Health, Medicine and Life Sciences, Brunel University London, Uxbridge, UK

${ }^{4}$ University of Nottingham Business School, Nottingham, UK

${ }^{5}$ School of Nursing, AHPs and Midwifery, University Hospitals Birmingham NHS Foundation Trust, Birmingham, UK

${ }^{6}$ NIHR Nottingham Biomedical Research Centre, Nottingham, UK

${ }^{7}$ University of Nottingham School of Health Sciences, Nottingham, UK

Twitter Amani Al-Oraibi @AmaniAlOraibi, Catrin Evans @Catrin_notts and Holly Blake@hollyblakenotts

Acknowledgements Ipsos MORI conducted the surveys. We would like to thank HEE, NHS England and NHS Improvement, Allie Carter Beverley Harden, Sarah Goodhew, Donna Poole and Charlotte Beardmore for their work to develop the surveys and engage with participants. We would also like to thank all those who took the time to take part in the surveys.

Contributors HB and JC designed the study, with input from CE, ST and RP. Data analysis was carried out by JH, LLF and AA-O. The manuscript was drafted by LJF, $A A-0$ and $H B$. LJF and AA-O are joint first authors with equal contribution, $H B$ is 
corresponding author. All authors accept full responsbility for the work and/or the conduct of the study, had access to the data, and controlled the decision to publish. All authors read and approved the final manuscript.

Funding This study has been funded by Health Education England (grant number ASA273 HKAUR-HEER).

Disclaimer The funding bodies had no role in the design, conduct, interpretation or writing of the report on this research.

Competing interests $\mathrm{JC}$ is a consultant to Health Education England.

Patient consent for publication Not required.

Ethics approval The Ipsos-MORI surveys were undertaken outside the NHS setting and NHS Research Ethics Committee (REC) review is not required for healthcare market research conducted by professional market researchers. Ipsos-MORI is an independent research agency bound by the rules of the Market Research Society. Informed consent for personal responses to be used by Ipsos-MORI and HEE for research purposes is assumed from the completion of the survey. Personal identifiers (name and contact details) were not available to the research team. There were no financial or other incentives and respondents were free to decide whether to participate. All data processing and storage comply with the General Data Protection Regulation and UK Data Protection Act 2018.

Provenance and peer review Not commissioned; externally peer reviewed.

Data availability statement Data are available upon reasonable request. Data are available on reasonable request. The data sets generated and analysed during the current study are not publicly available due to the integrity of participant privacy but are available from the corresponding author on reasonable request and if approved by HEE.

Supplemental material This content has been supplied by the author(s). It has not been vetted by BMJ Publishing Group Limited (BMJ) and may not have been peer-reviewed. Any opinions or recommendations discussed are solely those of the author(s) and are not endorsed by BMJ. BMJ disclaims all liability and responsibility arising from any reliance placed on the content. Where the content includes any translated material, BMJ does not warrant the accuracy and reliability of the translations (including but not limited to local regulations, clinical guidelines, terminology, drug names and drug dosages), and is not responsible for any error and/or omissions arising from translation and adaptation or otherwise.

Open access This is an open access article distributed in accordance with the Creative Commons Attribution Non Commercial (CC BY-NC 4.0) license, which permits others to distribute, remix, adapt, build upon this work non-commercially, and license their derivative works on different terms, provided the original work is properly cited, appropriate credit is given, any changes made indicated, and the use is non-commercial. See: http://creativecommons.org/licenses/by-nc/4.0/.

\section{ORCID iDs}

Amani Al-Oraibi http://orcid.org/0000-0003-1502-2627

Joy Conway http://orcid.org/0000-0001-6464-1526

Catrin Evans http://orcid.org/0000-0002-5338-2191

\section{REFERENCES}

1 de Bont A, van Exel J, Coretti S, et al. Reconfiguring health workforce: a case-based comparative study explaining the increasingly diverse professional roles in Europe. BMC Health Serv Res 2016;16.

2 Hooks C, Walker S. An exploration of the role of advanced clinical practitioners in the East of England. Br J Nurs 2020;29:864-9.

3 Evans C, Poku B, Pearce R, et al. Characterising the outcomes, impacts and implementation challenges of advanced clinical practice roles in the UK: a scoping review. BMJ Open 2021;11:e048171.
4 NHS Long Term Plan [Internet]. Available: https://www.longtermplan. nhs.uk/

5 Health Education England. Advanced Practice. Available: https:// www.hee.nhs.uk/our-work/advanced-clinical-practice

6 Bonsall K, Cheater FM. What is the impact of advanced primary care nursing roles on patients, nurses and their colleagues? A literature review. Int J Nurs Stud 2008;45:1090-102.

7 Maier CB, Aiken LH. Task shifting from physicians to nurses in primary care in 39 countries: a cross-country comparative study. Eur J Public Health 2016;26:927-34.

8 Evans C, Pearce R, Greaves S, et al. Advanced clinical practitioners in primary care in the UK: a qualitative study of workforce transformation. Int J Environ Res Public Health 2020;17:4500.

9 Stasa H, Cashin A, Buckley T, et al. Advancing advanced practice - clarifying the conceptual confusion. Nurse Educ Today 2014;34:356-61.

10 McDonnell A, Goodwin E, Kennedy F, et al. An evaluation of the implementation of advanced nurse practitioner (ANP) roles in an acute hospital setting. J Adv Nurs 2015;71:789-99. doi:10.1111/ jan. 12558

11 Leary A, Maclaine K, Trevatt P, et al. Variation in job titles within the nursing workforce. J Clin Nurs 2017;26:4945-50.

12 Evans C, Poku B, Pearce R, et al. Characterising the evidence base for advanced clinical practice in the UK: a scoping review protocol. BMJ Open 2020;10:e036192.

13 Health Education England, 2021. Available: https://www.hee.nhs.uk/

14 Nadaf C. Perspectives: reflections on a debate: when does advanced clinical practice stop being nursing? J Res Nurs 2018;23:91-7.

15 Centre for Advancing Practice T. Developing people health and healthcare. Workplace Supervision for Advanced Clinical Practice: An integrated multi-professional approach for practitioner development [Internet], 2021. Available: www.hee.nhs.uk

16 Zheng M. Conceptualization of cross-sectional mixed methods studies in health science: a methodological review. Int J Quantitative Qualitative Res Methods 2015;3.

17 Guetterman TC, Babchuk WA, Howell Smith MC, et al. Contemporary approaches to mixed Methods-Grounded theory research: a Field-Based analysis. J Mix Methods Res 2019;13:179-95.

18 Braun V, Clarke V. Using thematic analysis in psychology. Qual Res Psychol 2006;3:77-101

19 East L, Knowles K, Pettman M, et al. Advanced level nursing in England: organisational challenges and opportunities. J Nurs Manag 2015;23:1011-9.

20 Maier CB. The role of governance in implementing task-shifting from physicians to nurses in advanced roles in Europe, U.S., Canada, New Zealand and Australia. Health Policy 2015;119:1627-35.

21 Lawler J, Maclaine K, Leary A. Workforce experience of the implementation of an advanced clinical practice framework in England: a mixed methods evaluation. Hum Resour Health 2020;18:96.

22 Jones A, Powell T, Watkins D, et al. Realising their potential? Exploring interprofessional perceptions and potential of the advanced practitioner role: a qualitative analysis. BMJ Open 2015;5:e009740.

23 Brooten D, Youngblut JM, Deosires W, et al. Global considerations in measuring effectiveness of advanced practice nurses. Int $J$ Nurs Stud 2012;49:906-12.

24 Elliott N, Begley C, Kleinpell R, et al. The development of leadership outcome-indicators evaluating the contribution of clinical specialists and advanced practitioners to health care: a secondary analysis. $J$ Adv Nurs 2014;70:1078-93.

25 Price S, Reichert C. The importance of continuing professional development to career satisfaction and patient care: meeting the needs of novice to mid- to Late-Career nurses throughout their career span. Adm Sci 2017;7:17.

26 Tariq S, Woodman J. Using mixed methods in health research. JRSM Short Rep 2013:4:204253331347919. 